\title{
Susceptibility of group A beta-hemolytic streptococci in the lower St Lawrence region, Quebec
}

\author{
Annie DesRosiers $\mathrm{BSc}^{1}$, Patrick Dolcé MD FRCPC ${ }^{1}$, Philippe Jutras MD FRCPC ${ }^{1}$, Louise P Jetté BSc ${ }^{2}$
}

A DesRosiers, P Dolcé, P Jutras, LP Jetté. Susceptibility of group A beta-hemolytic streptococci in the lower St Lawrence region, Quebec, Canada. Can J Infect Dis 1999;10(4):279-285.

OBJECTIVE: To determine the susceptibility of group A beta-hemolytic streptococci (GABHS) in the lower St Lawrence region, Quebec to different antibiotics, particularly macrolides, and to compare different antibiogram methods (disk diffusion, E-test and microdilution) and incubation atmospheres (ambient air and 5\% carbon dioxide).

METHODS: A total of 384 strains of GABHS isolated from 377 patients (throat 335; other sites 49) from three hospitals in the lower St Lawrence region were analyzed for their susceptibility to erythromycin, clarithromycin, azithromycin, penicillin, clindamycin, cephalothin, rifampin and vancomycin by disk diffusion on Mueller-Hinton (MH) agar supplemented with $5 \%$ defibrinated sheep blood (MHB) at $35^{\circ} \mathrm{C}$ in $5 \%$ carbon dioxide. Strains that were found to be intermediately resistant or resistant to one of the antibiotics by disc diffusion, strains from sites other than throat, and a sample of 97 pharyngeal strains were evaluated by E-test on $\mathrm{MHB}\left(35^{\circ} \mathrm{C}, 5 \%\right.$ carbon dioxide) for their susceptibility to the antibiotics erythromycin, clarithromycin, azithromycin, penicillin, clindamycin and ceftriaxone. In addition, minimum inhibitory concentrations (MICs) were determined for erythromycin and azithromycin by broth microdilution using MH broth supplemented with $2.5 \%$ of lysed horse blood $\left(35^{\circ} \mathrm{C}\right.$, ambient air) on strains that were resistant or intermediately resistant to the macrolides (erythromycin, clarithromycin, azithromycin). An evaluation was also carried out on these strains to determine the influence of the incubating atmosphere (ambient air versus $5 \%$ carbon dioxide) on susceptibility results obtained by disk diffusion (erythromycin, clarithromycin and azithromycin) and E-test (erythromycin and azithromycin) methods.

RESULTS: Nine strains (2\%) from nine patients (throat eight, pus one) were resistant to all macrolides as tested by three different techniques (disk diffusion, E-test and microdilution). All strains were susceptible to all the other antibiotics tested. For the strains intermediately resistant or resistant to macrolides, incubation in a $5 \%$ carbon dioxide atmosphere was associated with a reduction in the diameter of inhibition determined by disk diffusion $(\mathrm{P}<0.001)$ with frequent minor variations in interpretation, and with an increase in the MIC by E-test $(\mathrm{P}<0.001)$, which had no impact on interpretation.

CONCLUSIONS: Resistance of GABHS to macrolides was not common (2\%) in the lower St Lawrence Region. GABHS susceptibility to erythromycin seemed to predict the susceptibility to the other macrolides. Significant variation in antibiogram results (disk diffusion and E-test) of GABHS susceptibility to macrolides was related to the incubation atmosphere and may have an impact on the interpretation of disk diffusion results.

Key Words: Antibiogram; Beta-hemolytic streptococci; Group A streptococci; Macrolides; Resistance; Streptococcus pyogenes

Pour le résumé, voir page suivante

\footnotetext{
${ }^{1}$ Centre Hospitalier Régional de Rimouski, Department of Medical Microbiology and Infectious Diseases, Rimouski, Québec; ${ }^{2}$ Laboratoire de Santé Publique du Québec, Sainte-Anne-de-Bellevue, Québec

Correspondence and reprints: Dr Patrick Dolcé, Department of Medical Microbiology and Infectious Diseases, Centre Hospitalier Régional de Rimouski, 150, Rouleau, Rimouski, Québec G5L 5T1. Telephone 418-724-8336, fax 418-724-8619, e-mail pdolce@globetrotter.net

Received for publication February 2, 1998. Accepted December 10, 1998
} 


\title{
Sensibilité des streptocoques bêta-hémolytiques du groupe A dans la région du Bas Saint-Laurent, au Québec
}

\begin{abstract}
OBJECTIF : Déterminer pour la région du Bas Saint-Laurent, au Québec, la sensibilité des streptocoques bêta-hémolytiques du groupe $\mathrm{A}$ (SBHGA) à l'endroit de divers antibiotiques, particulièrement des macrolides, et comparer les diverses méthodes d'antibiogramme (diffusion en gélose, test $\mathrm{E}$ et microdilution) et les atmosphère d'incubation (air ambiant et dioxyde de carbone à $5 \%$ ).

MÉTHODES : En tout, on a analysé 384 isolats de SBHGA provenant de 377 patients (gorge, 335; autres foyers, 49) de trois hôpitaux du Bas Saint-Laurent pour vérifier leur sensibilité à l'érythromycine, à la clarithromycine, à l'azithromycine, à la pénicilline, à la clindamicyne, à la céphalothine, au rifampim et à la vancomycine, par diffusion en gélose de Mueller-Hinton $(\mathrm{MH})$ enrichie de sang de mouton à $5 \%$ défibriné (SMD), à $35^{\circ} \mathrm{C}$, dans du dioxyde de carbone à $5 \%$. Les souches qui se sont révélées résistantes ou moyennement résistantes à l'un des antibiotiques par la méthode de diffusion en gélose, les souches provenant d'autres foyers que la gorge et un échantillon de 97 isolats pharyngés ont été évalués par test $\mathrm{E}$ sur $\mathrm{SMD}\left(35^{\circ} \mathrm{C}\right.$, dioxyde de carbone à $\left.5 \%\right)$ pour en mesurer la sensibilité à l'endroit des antibiotiques érythromycine, clarithromycine, azithromycine, pénicilline, clindamycine et ceftriaxone. De plus, les concentrations minimales inhibitrices (CMI) ont été calculées pour l'érythromycine et l'azithromycine par microdilution sur bouillon de culture, à l'aide de solutions $\mathrm{MH}$ auxquelles a été ajouté du sang de cheval à $2,5 \%$ lysé $\left(35^{\circ} \mathrm{C}\right.$, air ambiant), sur des souches qui se sont révélées résistantes ou moyennement résistantes à l'endroit des macrolides (érythromycine, clarithromycine, azithromycine). Une évaluation a en outre été effectuée sur ces souches afin de déterminer l'influence de l'atmosphère d'incubation (air ambiant vs dioxyde de carbone à $5 \%$ ) sur les résultats d'antibiogrammes obtenus par diffusion en gélose (érythromycine, clarithromycine et azithromycine) et test E (érythromycine et azithromycine).

RÉSULTATS : Neuf souches ( $2 \%$ provenant de neuf patients (8 prélèvements de gorge, 1 spécimen de pus) se sont révélées résistantes à tous les macrolides testés au moyen des trois techniques (diffusion en gélose, test $\mathrm{E}$ et microdilution). La totalité des souches se sont révélées sensibles à tous les autres antibiotiques testés. Pour les souches résistantes ou moyennement résistantes aux macrolides, l'incubation dans une atmosphère de dioxyde de carbone à $5 \%$ a été associée à une réduction du diamètre d'inhibition, déterminée par la méthode de diffusion en gélose $(\mathrm{p}<0,001)$, avec fréquentes variations mineures des interprétations et augmentation de la CMI selon le test $\mathrm{E}(\mathrm{p}<0,001)$, qui n'ont eu aucun impact sur l'interprétation de ces résultats.

CONCLUSIONS : La résistance des SBHGA à l'endroit des macrolides n'a pas été fréquente $(2 \%)$ dans le Bas Saint-Laurent. Leur sensibilité à l'érythromycine a semblé être un facteur de prévisibilité de leur sensibilité aux autres macrolides. La variabilité significative des résultats d'antibiogrammes (diffusion en gélose et test E), du degré de sensibilité des SBHGA à l'endroit des macrolides a été jugée en lien avec l'atmosphère d'incubation et pourrait exercer un impact sur l'interprétation des résultats obtenus au moyen de la technique par diffusion en gélose.
\end{abstract}

$I^{n}$ the past few years with the resurgence of invasive infections, group A beta-hemolytic streptococci (GABHS) have become a public health threat (1-8). Surveillance programs have been implemented in many countries. In Canada, in the province of Quebec, GABHS invasive infections became a notifiable disease in 1995 (unpublished data).

In 1995, 11 cases of invasive GABHS infections occurred in the lower St Lawrence region (LSLR) of Quebec. This region, with a population of approximately 215,000 people, had an incidence rate of 5.1/100 000 cases/year, the highest in the province of Quebec. The overall incidence rate in Quebec was 1.4/100,000 cases/year (unpublished data).

Pharyngitis is the most frequent clinical manifestation of GABHS infections, and it is believed that pharyngitis usually precedes invasive infections. Penicillin is the antibiotic of choice in the treatment of pharyngitis. Erythromycin is recommended as an alternative for patients allergic to penicillin $(9,110)$.

Recently, increasing resistance of GABHS to erythromycin and its derivatives has been observed in several countries. In Japan, the frequency of GABHS erythromycin resistance rose from $2 \%$ in 1971 to $50 \%$ to $70 \%$ in the 1990 s (11-13). A resistance of nearly $40 \%$ was reported in certain areas of Finland in 1990 (14-16) and was associated with the level of regional erythromycin consumption. Erythromycin resistance dropped to $8.6 \%$ after a successful nationwide information and education program to reduce erythromycin consumption (17). Such high levels of resistance have not been reported in North
America. For instance, the rate of erythromycin resistance is low in the United States: $5 \%$ and less, for studies published between 1968 and $1997(11,18,19)$. Very few Canadian studies have addressed the issue of GABHS resistance to macrolides. In 1992, Knowles et al (20) found $2 \%$ erythromycin resistance among 492 GABHS isolates from clinical specimens gathered from in a children's hospital in Montreal. They also reported that, in comparison with ambient air, incubation under a $5 \%$ carbon dioxide atmosphere was associated with a significant increase in minimal inhibition concentration (MIC) for GABHS isolates to erythromycin and clarithromycin. A similar effect of incubation atmosphere was described by Brorson and Larsson (21).

The aim of the present study was to determine the susceptibility level of GABHS to different antibiotics, particularly macrolides, in the LSLR. In addition, the study compared different antibiogram methods (disk diffusion, E-test and microdilution) and two incubation atmospheres (ambient air and 5\% carbon dioxide) in a subset of isolates.

\section{MATERIALS AND METHODS}

GABHS strains: GABHS isolates were collected between March 1995 and February 1996 from three hospitals in the LSLR: the Centre Hospitalier Régional de Rimouski, the Centre Hospitalier d'Amqui and the Centre Hospitalier du Grand Portage. A maximum of two strains per patient were admissible: one strain from the throat and the other from a normally sterile site. 
TABLE 1

Sources of the 384 group A beta-hemolytic streptococci clinical strains used to study antibiotic resistance in the lower St Lawrence region, Quebec

\begin{tabular}{lcc}
\hline Sites & Number of strains & (\%) \\
\hline Throat & 335 & 87.2 \\
Wound/pus & 35 & 9.1 \\
Blood & 8 & 2.1 \\
Female genital tract & 5 & 1.3 \\
Bronchial secretion & 1 & 0.3 \\
Total & 384 & 100.0 \\
\hline
\end{tabular}

Conservation and reidentification: Pure cultures of strains were stored in glycerol broth at $-70^{\circ} \mathrm{C}$. Frozen isolates were passaged twice on sheep blood agar (ambient air, $35^{\circ} \mathrm{C}$ for 18 to $24 \mathrm{~h}$ ) before testing. Reidentification of all the strains was carried out based on the following criteria: presence of betahemolysis on blood sheep agar, presence of Gram-positive cocci on Gram stain, negative catalase, susceptibility to 0.04 units of bacitracin (DIFCO Laboratories, Detroit, Michigan), resistance to trimethoprim/sulphamethoxazole $1.25 \mathrm{~g} / 23.75 \mathrm{~g}$ (BBL Sensi-Disk, Becton Dickinson Microbiology Systems, Cockeysville, Maryland), and positive reaction to hydrolysis of L-pyrrolidonyl-beta-naphthylamine (PYR test) (Sigma Chemical Company, St Louis, Missouri) detected by adding $N, N$-dimethylaminocinnamaldehyde (BioMerieux Vitek Inc, Hazelwood, Missouri). A specific agglutination against group A antigen (Patho-Dx, Diagnostic Products Corporation, Los Angeles, California) was performed on strains for which any of the above identification criteria were not in agreement.

Antibiotic susceptibility testing-Disk diffusion: All strains were tested by disk diffusion on Mueller-Hinton (MH) agar (Quelab, Montreal, Quebec) supplemented with 5\% sheep blood (MHB) in accordance with the National Committee for Clinical Laboratory Standards (NCCLS) (Wayne, Pennsylvania) (5\% carbon dioxide, 20 to $24 \mathrm{~h}$ ) (22). The following antibiotics were tested (BBL Sensi-Disk): erythromycin (15 g), clarithromycin (15 g), azithromycin (15 g) (DIFCO), penicillin (10 units), cephalothin (30 g), rifampin (5 g), clindamycin (2 g) and vancomycin $(30 \mathrm{~g})$. Results were interpreted according to NCCLS guidelines (23). Because no guidelines were available for rifampin and cephalothin, interpretation for rifampin used the Streptococcus pneumoniae guidelines, and interpretation for cephalothin used the data for organisms other than Neisseria gonorrheae, Haemophilus species and $S$ pneumoniae (23).

MIC by E-test: Strains that were resistant or intermediately resistant by disk diffusion, strains from sites other than the throat and a sample of 97 pharyngeal strains were evaluated by E-test. Incubation conditions were identical to those for disk diffusion (MHB, 5\% carbon dioxide, $35^{\circ} \mathrm{C}, 20$ to $24 \mathrm{~h}$ ). The antibiotics (AB Biodisk, Solna, Sweden) tested were erythromycin, clarithromycin, azithromycin, penicillin, clindamycin and ceftriaxone.

MIC by microdilution: MIC values were determined for erythromycin (Sigma Chemical Company) and azithromycin (Pfizer
TABLE 2

Susceptibility of the $\mathbf{3 8 4}$ group A beta-hemolytic streptococci strains determined by disk diffusion in 5\% carbon dioxide atmosphere

\begin{tabular}{lccc}
\hline Antibiotic & Susceptible & Intermediate & Resistant \\
\hline Erythromycin & 374 & 1 & 9 \\
Clarithromycin & 375 & 1 & 8 \\
Azithromycin & 375 & 0 & 9 \\
Penicillin & 384 & 0 & 0 \\
Cephalothin & 384 & 0 & 0 \\
Rifampin & 384 & 0 & 0 \\
Clindamycin & 384 & 0 & 0 \\
Vancomycin & 384 & 0 & 0 \\
\hline
\end{tabular}

Canada Inc, Pointe-Claire, Quebec) by broth microdilution using MH broth supplemented with $2.5 \%$ of lysed horse blood (ambient air, $35^{\circ} \mathrm{C}$ ) in accordance with NCCLS standards (24) for strains that were resistant or intermediately resistant to macrolides by either disk diffusion or E-test. This evaluation was performed at the provincial reference laboratory, the Laboratoire de Santé Publique du Québec, Sainte-Anne-deBellevue, Québec.

Evaluation of the influence of incubation atmosphere for macrolides: The susceptibilities of strains that were found to be resistant or intermediately resistant to erythromycin or its derivatives by disk diffusion or E-test were re-examined in ambient air and 5\% carbon dioxide. The antibiotics tested by disk diffusion were erythromycin, clarithromycin and azithromycin. Erythromycin and azithromycin were tested by E-test. These tests were done in parallel and in triplicate.

Quality control: $S$ pneumoniae ATCC 49619, Streptococcus pyogenes ATCC 19615 and S pyogenes LSPQ/MA-3485 were included as controls. S pyogenes LSPQ/MA-3485, a strain known to be erythromycin resistant (MIC greater than $16 \mathrm{mg} / \mathrm{L}$ ), was provided by the Laboratoire de Santé Publique du Quebec.

Statistical analysis: Data were analyzed on EPI INFO, version 6.0 (Atlanta, Georgia). The influence of the incubation atmosphere (ambient air versus carbon dioxide) was determined by ANOVA with a significance level of $\mathrm{P}<0.05$ using SYSTAT software, version 5.02 (Systat Inc, Evanston, Illinois).

Review of the medical files: The medical files of patients with strains resistant or intermediately resistant to macrolides were reviewed to obtain any pertinent clinical data.

\section{RESULTS}

A total of 384 GABHS strains isolated from 377 patients (throat 335 [87\%], other sites 49 [13\%]) were examined (Table 1). Seven patients had two isolates: one from the throat and the second from another site (wound four, fascia two, joint liquid one). Fifteen of the 49 nonpharyngeal strains were isolated in patients with invasive infections. The re-identification of all 384 strains confirmed them to be $S$ pyogenes. Only six isolates yielded unexpected results; all exhibited trimethoprim/sulphamethoxazole susceptibility. In these cases, seroagglutination with group A antigen gave positive results. 
TABLE 3

Susceptibility of 155 strains of group A beta-hemolytic streptococci determined by E-test in $5 \%$ carbon dioxide atmosphere

\begin{tabular}{lcccccc}
\hline Antibiotic & $\mathbf{S}$ & $\mathbf{I}$ & $\mathbf{R}$ & $\mathbf{M I C}_{\mathbf{5 0}}(\boldsymbol{\mu g} / \mathbf{m L})$ & $\mathbf{M I C}_{\mathbf{9 0}}(\boldsymbol{\mu g} / \mathbf{m L})$ & $\mathbf{R a n g e}(\boldsymbol{\mu g} / \mathbf{m L})$ \\
\hline Erythromycin & 146 & 0 & 9 & 0.064 & 0.125 & 0.047 \\
Clarithromycin & 146 & 0 & 9 & 0.032 & $0.032-24$ & $0.016-12$ \\
Azithromycin & 146 & 0 & 9 & 0.012 & 0.016 & $0.094->256$ \\
Penicillin & 155 & 0 & 9 & 0.047 & 0.094 & $0.002-0.032$ \\
Clindamycin & 155 & 0 & 9 & 0.016 & 0.023 & $0.016-0.25$ \\
Ceftriaxone & 155 & 0 & 9 & $0.016-0.32$ \\
\hline
\end{tabular}

I Intermediate; MIC Minimum inhibitory concentration; R Resistant; S Susceptible

\section{TABLE 4}

Microdilution minimum inhibitory concentration (MIC) for erythromycin and azithromycin, and antibiogram interpretation for the 10 isolates of group A beta-hemolytic streptococci screened as not sensitive to macrolides

\begin{tabular}{lcr}
\hline Strain number & $\begin{array}{c}\text { Erythromycin MIC } \\
(\boldsymbol{\mu} \mathbf{g} / \mathbf{m L})\end{array}$ & $\begin{array}{r}\text { Azithromycin MIC } \\
(\boldsymbol{\mu} \mathbf{g} / \mathbf{m L})\end{array}$ \\
\hline 1 & $0.06(\mathrm{~S})$ & $0.12(\mathrm{~S})$ \\
2 & $4(\mathrm{R})$ & $256(\mathrm{R})$ \\
3 & $4(\mathrm{R})$ & $128(\mathrm{R})$ \\
4 & $4(\mathrm{R})$ & $128(\mathrm{R})$ \\
5 & $4(\mathrm{R})$ & $128(\mathrm{R})$ \\
6 & $4(\mathrm{R})$ & $256(\mathrm{R})$ \\
7 & $4(\mathrm{R})$ & $128(\mathrm{R})$ \\
8 & $4(\mathrm{R})$ & $256(\mathrm{R})$ \\
9 & $4(\mathrm{R})$ & $256(\mathrm{R})$ \\
10 & $16(\mathrm{R})$ & $16(\mathrm{R})$ \\
\hline
\end{tabular}

R Resistant; S Susceptible

Susceptibility testing: All strains were susceptible to penicillin, cephalothin, rifampin, clindamycin and vancomycin when tested by disk diffusion in an atmosphere enriched with $5 \%$ carbon dioxide (Table 2). A total of 10 isolates showed some level of resistance to one of the macrolides. These strains were isolated from the throat in nine cases of pharyngitis (strains 1 to 9) and from pus drained from an ischiorectal abscess in one case (strain 10). Strain 1 was repeatedly intermediately resistant to erythromycin and susceptible to clarithromycin and azithromycin. Strain 2 was intermediately resistant to clarithromycin, and resistant to erythromycin and azithromycin. Eight isolates (strains 3-10) were resistant to azithromycin, clarithromycin and erythromycin.

Susceptibility determined by E-test (5\% carbon dioxide) showed similar results to disk diffusion. Nine of the 155 strains (strains 2 to 10 ) tested were resistant to all macrolides by E-test (Table 3). It is noteworthy that strain 2 , which was intermediately resistant to clarithromycin by disk diffusion, was found resistant by E-test. Also, strain 1 was found susceptible to all antibiotics by E-test, including macrolides, while it was intermediately resistant to erythromycin by disk diffusion. All strains were susceptible to penicillin, clindamycin and ceftriaxone. The MIC90 values showed that clarithromycin (MIC90 $0.047 \mathrm{mg} / \mathrm{L}$ ) was more active than erythromycin ( $\left.\mathrm{MIC}_{90} 0.125 \mathrm{mg} / \mathrm{L}\right)$, which was more active than azithromycin ( $\mathrm{MIC}_{90} 0.38 \mathrm{mg} / \mathrm{L}$ ) (Table 3).

Strains 1 to 10 were tested by microdilution for erythromycin and azithromycin. As in the case of E-test results, strain 1 was susceptible to both agents, and the others were resistant (Table 4).

Effect of incubation atmosphere on disk diffusion and Etest results: The antibiograms of strains 1 to 10 were examined in parallel in ambient air and in carbon dioxide by disk dif-

TABLE 5

Effect of the incubating atmosphere (5\% carbon dioxide $\left[\mathrm{CO}_{2}\right]$ versus ambient air) on the mean diameters of inhibition and the antibiogram interpretation to macrolides determined by disk diffusion for 10 isolates of group A beta-hemolytic streptococci screened as not sensitive to macrolides

\begin{tabular}{|c|c|c|c|c|c|c|}
\hline \multirow[b]{2}{*}{ Strain number } & \multicolumn{2}{|c|}{ Erythromycin $(\mathrm{mm})$} & \multicolumn{2}{|c|}{ Clarithromycin (mm) } & \multicolumn{2}{|c|}{ Azithromycin (mm) } \\
\hline & $5 \% \mathrm{CO}_{2}$ & Ambient air & $5 \% \mathrm{CO}_{2}$ & Ambient air & $5 \% \mathrm{CO}_{2}$ & Ambient air \\
\hline 1 & $20.4(\mathrm{I})$ & $24.9(\mathrm{~S})$ & $23.3(\mathrm{~S})$ & $24.9(\mathrm{~S})$ & $20.8(S)$ & $22.5(\mathrm{~S})$ \\
\hline 2 & $14.7(\mathrm{R})$ & 16.5 (I) & 18.6 (I) & 19.5 (I) & $9.3(\mathrm{R})$ & $10.7(\mathrm{R})$ \\
\hline 3 & $10.0(\mathrm{R})$ & $13.4(\mathrm{R})$ & $12.3(\mathrm{R})$ & $15.6(\mathrm{R})$ & $6.5(\mathrm{R})$ & $10.2(\mathrm{R})$ \\
\hline 4 & $11.5(\mathrm{R})$ & 17.8 (I) & $14.5(\mathrm{R})$ & $22.4(\mathrm{~S})$ & $8.5(\mathrm{R})$ & 14.1 (I) \\
\hline 5 & $11.7(\mathrm{R})$ & $18.8(\mathrm{I})$ & $14.4(\mathrm{R})$ & $18.4(\mathrm{I})$ & $7.4(\mathrm{R})$ & $11.9(R)$ \\
\hline 6 & $10.8(\mathrm{R})$ & $18.3(\mathrm{I})$ & $14.8(\mathrm{R})$ & $19.0(\mathrm{I})$ & $8.0(\mathrm{R})$ & $12.3(\mathrm{R})$ \\
\hline 7 & $10.3(\mathrm{R})$ & $18.3(\mathrm{I})$ & $14.7(\mathrm{R})$ & 19.7 (I) & $8.8(R)$ & $13.2(\mathrm{R})$ \\
\hline 8 & $12.7(\mathrm{R})$ & $18.4(\mathrm{I})$ & $13.6(\mathrm{R})$ & $21.5(\mathrm{I})$ & $9.0(\mathrm{R})$ & $11.8(R)$ \\
\hline 9 & $11.5(\mathrm{R})$ & $15.7(\mathrm{R})$ & $14.4(\mathrm{R})$ & $18.8(\mathrm{I})$ & $8.3(\mathrm{R})$ & $11.9(\mathrm{R})$ \\
\hline 10 & $11.2(\mathrm{R})$ & $12.2(\mathrm{R})$ & $14.2(\mathrm{R})$ & $14.5(\mathrm{R})$ & $12.5(\mathrm{R})$ & 15.7 (I) \\
\hline
\end{tabular}

I Intermediate; R Resistant; S Susceptible 
TABLE 6

Effect of the incubating atmosphere (5\% carbon dioxide versus ambient air) on the modal minimum inhibitory concentration (MIC) and the antibiogram interpretation to erythromycin and azithromycin determined by E-test for the 10 isolates of group A beta-hemolytic streptococci screened as not sensitive to macrolides

\begin{tabular}{|c|c|c|c|c|}
\hline \multirow[b]{2}{*}{ Strain number } & \multicolumn{2}{|c|}{ Erythromycin MIC $(\mu \mathrm{g} / \mathrm{mL})$} & \multicolumn{2}{|c|}{ Azithromycin MIC $(\mu \mathrm{g} / \mathrm{mL})$} \\
\hline & Carbon dioxide & Ambient air & Carbon dioxide & Ambient air \\
\hline 1 & $0.094(\mathrm{~S})$ & $0.047(\mathrm{~S})$ & $0.38(\mathrm{~S})$ & $0.064(\mathrm{~S})$ \\
\hline 3 & $8(\mathrm{R})$ & $4(\mathrm{R})$ & $>256(\mathrm{R})$ & $16(\mathrm{R})$ \\
\hline 4 & $8(\mathrm{R})$ & $2(\mathrm{R})$ & $>256(\mathrm{R})$ & $12(\mathrm{R})$ \\
\hline 7 & $12(\mathrm{R})$ & $3(\mathrm{R})$ & $>256(\mathrm{R})$ & $16(R)$ \\
\hline 8 & $8(\mathrm{R})$ & $3(\mathrm{R})$ & $>256(\mathrm{R})$ & $16(R)$ \\
\hline 9 & $8(\mathrm{R})$ & $3(\mathrm{R})$ & $>256(\mathrm{R})$ & $16(R)$ \\
\hline 10 & $24(\mathrm{R})$ & $16(\mathrm{R})$ & $24(\mathrm{R})$ & $12(\mathrm{R})$ \\
\hline
\end{tabular}

I Intermediate; R Resistant; S Susceptible

fusion (erythromycin, clarithromycin, azithromycin) and E-test (erythromycin, azithromycin). With the disk diffusion technique (Table 5), the diameters of inhibition were significantly lower in carbon dioxide $(\mathrm{P}<0.001)$ than in ambient air, with frequent minor errors in interpretation observed between the two different incubating atmospheres. The distribution of minor errors was as follows: seven with erythromycin, five with clarithromycin and two with azithromycin. Only one major error in interpretation was observed: strain 4 for clarithromycin. MIC values obtained by E-test were significantly higher $(\mathrm{P}<0.001)$ in carbon dioxide than in ambient air (Table 6) and had no effect on interpretation. However, the variation in MIC values varied with the antibiotic. In fact, the $5 \%$ carbon dioxide atmosphere was associated with a one- to twofold increase in MIC values for erythromycin, while a two- to fourfold increase was observed for azithromycin.

Patient file review: The nine patients with macrolideresistant isolates (strains 2-10) had a mean age of 12 years (range six to 37), and eight were male. Follow-up was possible for seven patients. Penicillin was used in six cases. One patient received erythromycin for streptococcal pharyngitis (strain 7), but no data were available for the follow-up. All seven patients (including the case of the ischiorectal abscess) had an uneventful course.

\section{DISCUSSION}

This study shows that GABHS resistance to erythromycin, azithromycin or clarithromycin is uncommon (nine of $377 \mathrm{pa}$ tients, $2 \%$ ) in the LSLR. It is difficult to extrapolate the prevalence of resistance to other areas of Quebec or Canada, but these results are in agreement with other published North American studies reporting resistance rates of $5 \%$ or less. The increase of macrolide resistance noted in Scandinavian countries was associated with a high level of local erythromycin consumption. This aspect was not evaluated in this paper, but it would have been interesting to look at the local consumption of macrolides in our population.
During the analysis, strain 1 was not retained as a resistant strain, although it was repeatedly demonstrated to be intermediately resistant to only erythromycin by disk diffusion in $5 \%$ carbon dioxide. This result was not confirmed by E-test or by microdilution MIC. Therefore, isolates that are intermediately resistant or resistant to only one macrolide by disk diffusion testing should have this finding confirmed by E-test or microdilution MIC.

As reported in other studies $(18,19,25-27)$, crossresistance among erythromycin, azithromycin and clarithromycin was observed, and clarithromycin showed greater antimicrobial activity than erythromycin, which in turn was more active than azithromycin. Also, all of the GABHS strains were susceptible to all other antibiotics tested (penicillin, cephalothin, ceftriaxone, clindamycin, vancomycin and rifampin).

No resistance to clindamycin was observed in the strains resistant to erythromycin and derivatives in this study. Recently, this has been described as the $M$ phenotype of the macrolide-lincosamide-streptogramin B resistance pattern, which is frequently encountered in streptococcal strains (27-30). The mechanism of this resistance is believed to be an efflux system, while a ribosomal target modification is more commonly encountered with cross-resistance to macrolides and lincosamides.

For the subset of 10 isolates screened as not susceptible to macrolides, the incubation atmosphere $(5 \%$ carbon dioxide versus ambient air) had a significant effect on the antibiogram results obtained by disk diffusion or E-test. Testing for GABHS susceptibility to macrolides performed in 5\% carbon dioxide atmosphere resulted in a decrease in the diameters of inhibition by disk diffusion and an increase in MIC values for the E-test method. Brorson and Larsson (31) found similar results for erythromycin. It is known that the activity of erythromycin is reduced at lower $\mathrm{pH}$ (21). This might be a factor under a carbon dioxide-enriched atmosphere. Variations in interpretation of susceptibility test results were frequently ob- 
served between atmospheres enriched with $5 \%$ carbon dioxide and ambient air, resulting in minor errors mainly with disk diffusion. Compared with the microdilution reference technique, this evaluation, although incomplete, supports the use of carbon dioxide with both disk diffusion and E-test for the determination of macrolide susceptibility because only a single discrepancy was found. Testing a larger number of strains, including sensitive strains, would have given more conclusive results.

Recent guidelines from NCCLS clearly state that antibiograms by disk diffusion for streptococci, including GABHS, should be performed in $5 \%$ carbon dioxide (32-34). This statement on incubation conditions clarifies a major issue in thie performance of this technique. No guidelines have been published for the E-test, but we feel that atmospheres enriched with $5 \%$ carbon dioxide should also be used to ensure that the resistant strains are detected.

No evaluation of the clinical impact of GABHS resistance to macrolides could be undertaken because only one patient with a resistant strain received erythromycin for pharyngitis and no follow-up was available.

\section{REFERENCES}

1. Bisno AL. Group A streptococcal infections and acute rheumatic fever. N Engl J Med 1991;325:783-93.

2. Chelsom J, Halstensen A, Haga T, Hoiby EA. Necrotising fasciitis due to group A streptococci in western Norway: incidence and clinical features. Lancet 1994;344:1111-5.

3. Cone LA, Woodard DR, Schlievert PM, Tomory GS. Clinical and bacteriologic observations of a toxic shock-like syndrome due to Streptococcus pyogenes. N Engl J Med 1987;317:146-9.

4. Conly JM. Resurgence of virulent group A streptococcal infections: the streptococcal toxic shock syndrome. Can J Infect Dis 1992:3:222-3.

5. Hoge CW, Schwartz B, Talkington DF, Breiman RF, MacNeill EM, Englender, SJ. The changing epidemiology of invasive Group A streptococcal infections and the emergence of streptococcal toxic shock-like syndrome. A retrospective population-based study. JAMA 1993;269:384-9.

6. Stevens DL. Invasive group A streptococcus infections. Clin Infect Dis 1992;14:2-11.

7. Stevens DL, Tanner MH, Winship J, et al. Severe group A streptococcal infections associated with a toxic shock-like syndrome and scarlet fever toxin A. N Engl J Med 1989;321:1-7.

8. Demers B, Simor AE, Vellend H, et al. Severe invasive group A streptococcal infections in Ontario, Canada: 1987-1991. Clin Infect Dis 1993;16:792-800.

9. American Academy of Pediatrics. Group A streptococcal infections. In: Peter G. Red Book: Report of the Committee on Infectious Disease, 23rd edn. Elk Grove Village: American Academy of Pediatrics, 1994:430-9.

10. Bisno AL. Streptococcus pyogenes. In: Mandell GL, Bennett JE, Dolin R, eds. Principles and Practice of Infectious Diseases, 4th edn. New York: Churchill Livingstone, 1995:1786-99.

11. Gerber MA. Antibiotic resistance in group A streptococci. Pediatr Clin North Am 1995;42:539-51.

12. Maruyama S, Yoshioka H, Fujita K, Takimoto M, Satake Y. Sensivity of group A streptococci to antibiotics. Prevalence of resistance to erythromycin in Japan. Am J Dis Child 1979;133:1143-5.

13. Miyamoto Y, Takizawa K, Matsushima A, Asai Y, Nakatsuka S. Stepwise acquisition of multiple drug resistance by beta-hemolytic streptococci and difference in resistance patterns by type. Antimicrob Agents Chemother 1978;13:399-404.

14. O'Brien TF. Global surveillance of antibiotic resistance. N Engl J Med 1992;326:339-40.

15. Seppälä H, Klaukka T, Lehtonnen R, Nenonen E, Huovinen P.

\section{CONCLUSIONS}

The resistance of GABHS to macrolides was not frequent $(2 \%)$ in the LSLR of Quebec. GABHS susceptibility to erythromycin seemed to predict susceptibility to clarithromycin and azithromycin. A comparison of incubation in 5\% carbon dioxide or ambient air showed significant variation in antibiogram results (disk diffusion and E-test) for macrolides, which had a potential impact on the interpretation for disk diffusion. Thus, the recent guidelines from NCCLS should be followed, ensuring that atmospheres enriched with carbon dioxide are used when antibiotic susceptibility tests are performed by disk diffusion. The authors believe that atmospheres enriched with carbon dioxide should also be used for the E-test method.

ACKNOWLEDGEMENTS: The authors acknowledge Pfizer Canada, Hoffman-Laroche and $\mathrm{AB}$ Biodisk for their support. We also give thanks to Ms Christiane Parent and Ms Suzanne Desrosiers for their technical assistance, Ms Linda Gagnon (Centre Hospitalier d'Amqui) and Dr Pierre Harvey (Centre Hospitalier du Grand Portage) for providing additional strains, and Dr John Vary for reviewing the manuscript.

Outpatient use of erythromycin: link to increased erythromycin resistance in group A streptococci. Clin Infect Dis 1995;21:1378-85.

16. Seppälä $H$, Nissinen A, Järvinen $H$, et al. Resistance to erythromycin in group A streptococci. N Engl J Med 1992;326:292-7.

17. Seppälä H, Klaukka T, Vuopio-Varkila J, et al. The effect of changes in the consumption of macrolide antibiotics on erythromycin resistance in group A streptococci in Finland. Finnish Study Group for Antimicrobial Resistance. N Engl J Med 1997;337:441-6.

18. Coonan KM, Kaplan EL. In vitro susceptibility of recent North American group A streptococcal isolates to eleven oral antibiotics. Pediatr Infect Dis J 1994;13:630-5.

19. Carroll KC, Monroe P, Cohen, S, et al. Susceptibility of beta-hemolytic streptococci to nine antimicrobial agents among four medical centres in Salt Lake City, Utah, USA. Diagn Microbiol Infect Dis 1997;27:123-8.

20. Knowles K, Ringuette L, Lorange M, Massicotte L, Svenson J, Sorger S. Sensibilité aux antibiotiques de streptocoques du groupe A isolés chez des enfants. 18th Annual meeting of Association des médecins microbiologistes infectiologues du Québec. Montréal, June 1993. (Abst 22)

21. Brorson JE, Larsson P. The regression line for erythromycin is not valid for beta-hemolytic streptococci group A. Scand J Infect Dis 1987;19:243-6.

22. National Committee for Clinical Laboratory Standards. Performance standards for antimicrobial disk susceptibility tests [Document M2-A5]. Wayne: NCCLS, 1995.

23. National Committee for Clinical Laboratory Standards. Performance standards for antimicrobial disk susceptibility tests [Document M100-S6]. Wayne: NCCLS, 1993.

24. National Committee for Clinical Laboratory Standards. Methods for dilution antimicrobial susceptibility test for bacteria that grow aerobically [Document M7-A3]. Wayne: NCCLS, 1993.

25. Eisenberg E, Barza M. Azithromycin and clarithromycin. In: Remington JS, Swartz, MN. Current Clinical Topics in Infectious Disease. New York: Blackwell Scientific Publications, 1989:52-79.

26. Clarithromycin and azithromycin. Med Lett 1992;34:45-7.

27. Van Asselt GJ, Sloos JH, Mouton RP, Van Boven CPA, Van de Klundert JAM. Susceptibility of Streptococcus pyogenes to azithromycin, clarithromycin, erythromycin and roxithromycin in vitro. J Med Microbiol 1995;43:386-91.

28. Sutcliffe J, Tait-Kamradt A, Wondrack L. Streptococcus 
pneumoniae and Streptococcus pyogenes resistant to macrolides but sensitive to clindamycin: a common resistance pattern mediated by an efflux system. Antimicrob Agents Chemother 1996;40:1817-24.

29. Weisblum B. Erythromycin resistance by ribosome modification. Antimicrob Agents Chemother 1995;39:577-85.

30. Cornaglia G, Ligozzi M, Mazzariol A, e Valentini M, Orefici G, Fontana R. Rapid increase of resistance to erythromycin and clindamycin in Streptococcus pyogenes in Italy, 1993-1995. Emerg Infect Dis 1996;2:339-42.

31. Brorson J-E, Larsson P. pH and incubation atmosphere influence erythromycin activity against Branhamella catarrhalis J Antimicrob Chemother 1985;15:644-5.

32. National Committee for Clinical Laboratory Standards. Performance standards for antimicrobial disk susceptibility tests [Document M2-A6]. Wayne: NCCLS, 1997.

33. National Committee for Clinical Laboratory Standards. Performance standards for antimicrobial disk susceptibility tests. [Document M100-S7]. Wayne: NCCLS, 1997.

34. National Committee for Clinical Laboratory Standards. Performance standards for antimicrobial disk susceptibility tests. [Document M100-8]. Wayne: NCCLS, 1998. 


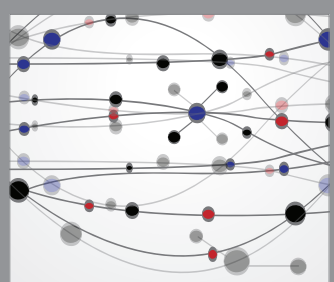

The Scientific World Journal
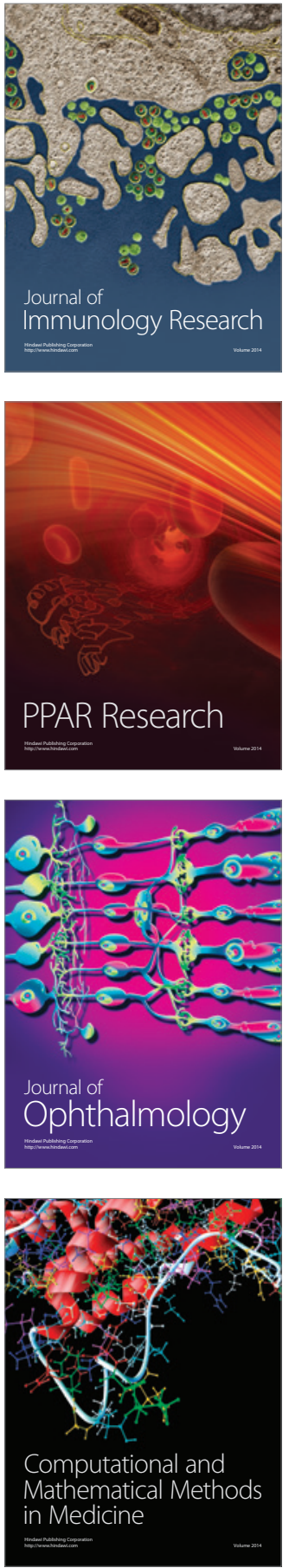

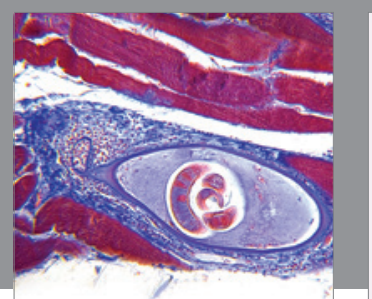

Gastroenterology Research and Practice

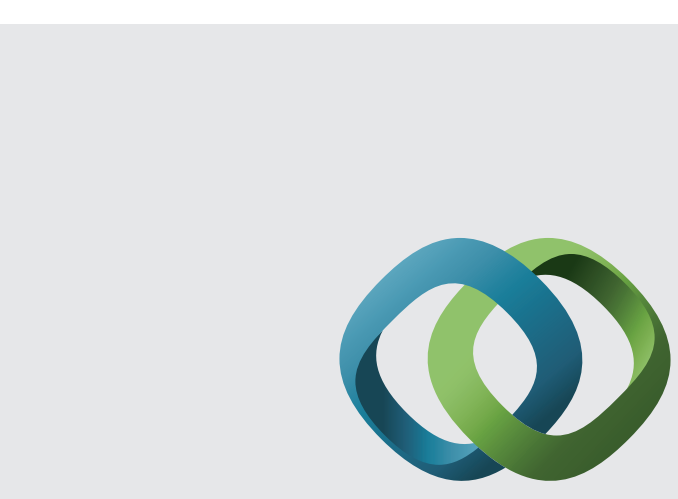

\section{Hindawi}

Submit your manuscripts at

http://www.hindawi.com
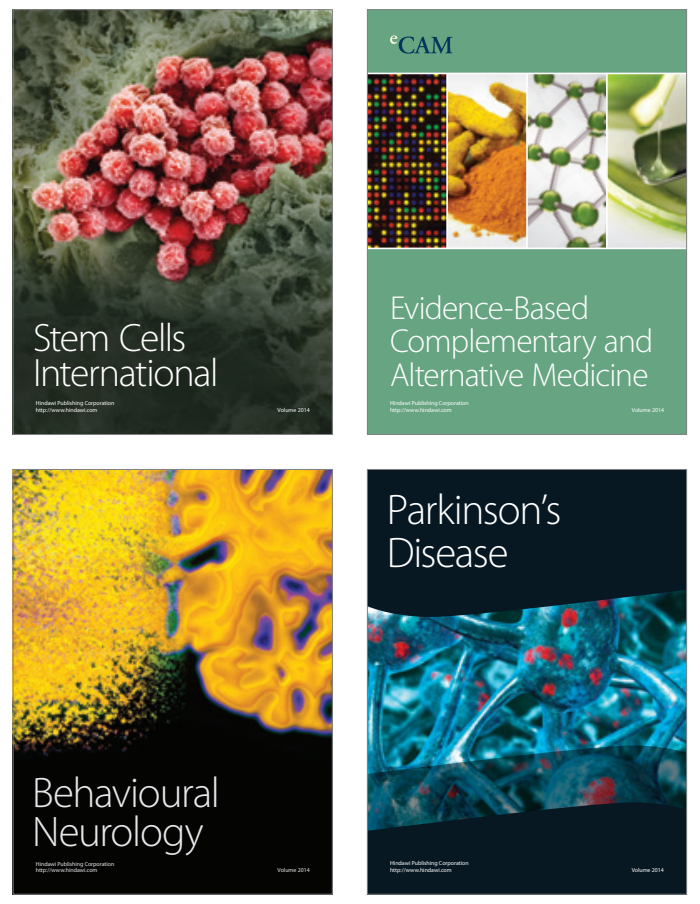
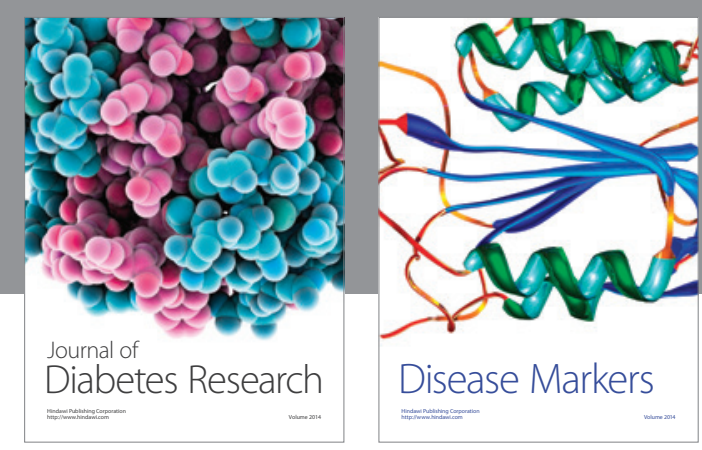

Disease Markers
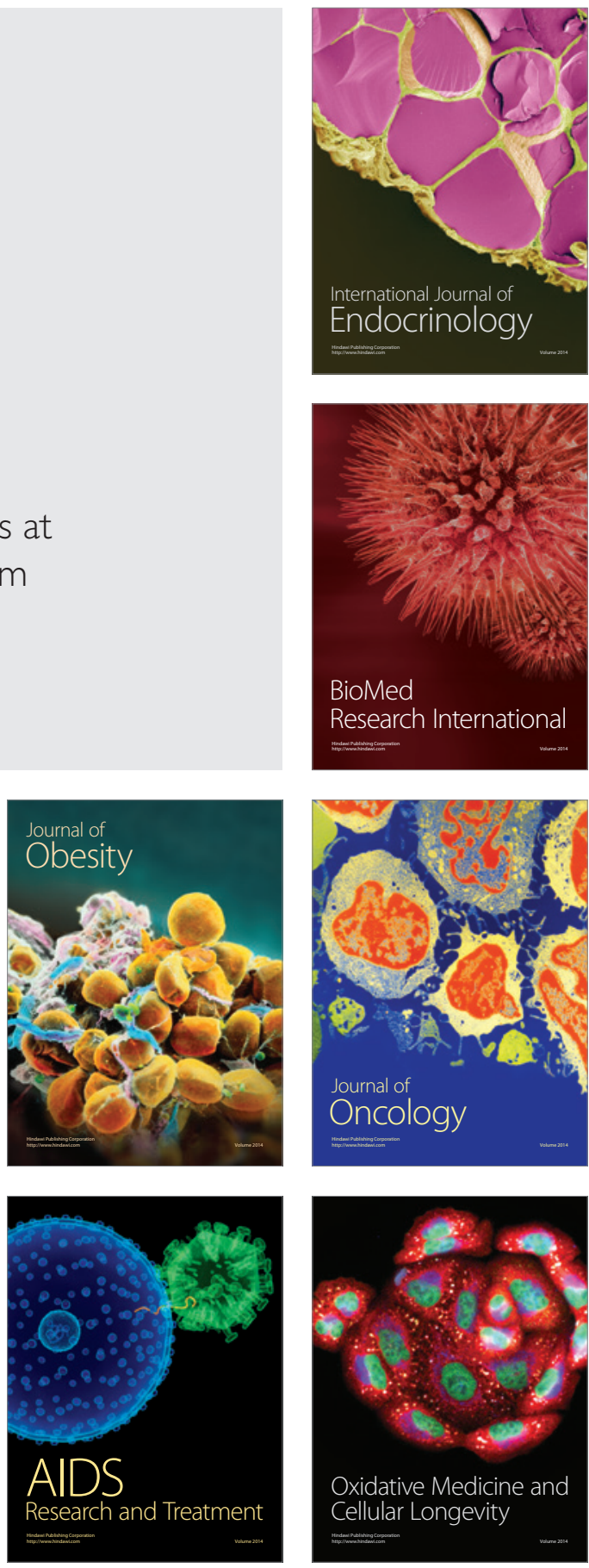